Session 3263

\title{
Interactive 3D Multimedia Cases for Manufacturing Engineering Education with Internet Support
}

\author{
Paul G. Ranky \\ Professor, The Department of Industrial and Manufacturing Systems Engineering, \\ New Jersey Institute of Technology, MERC (Multi-lifecycle Engineering Research \\ Center), Newark, NJ, 07102, USA. Email: ranky@niit.edu
}

\begin{abstract}
The objective of this research was to create a case-based / problem-based teaching and learning curriculum that enables students to explore design and manufacturing engineering, management, biomedical engineering, computer systems and other subjects with the aid of a generic architecture, that includes 3D web-browser readable multimedia, text, images, interactive videos, active codes for calculations, and even self-assessment tools (as spreadsheets and spreadsheet templates).

In this paper we introduce the principles of our educational methods and solution, and explain and demonstrate (during our presentation) a series of case-based learning modules that encourage reusable interactive multimedia development, team-oriented learning and problem-solving with real-world challenges, focusing on manufacturing engineering and technology education.
\end{abstract}

Our efforts are supported by over 30 academic and industrial partners, assuring the diversity, the relevance and the quality of this rapidly growing library and teaching / learning method.

\section{Introduction}

In the advanced learning environment Case-based / Problem-based Learning (PBL) is performed using web-enabled, 3D Virtual Reality interactive multimedia with optional online tutor support in an asynchronous fashion. This allows instruction to be de-coupled from a fixed schedule live classroom, enabling enjoyable interaction, feedback and assessment of learning and problem-solving literally anywhere, anytime. Problem-based learning is by its nature very interdisciplinary ([1], [2] and [3]).

Our approach mirrors real-world issues as closely as possible in an open source, 
networked virtual classroom, i.e. on the students' laptop monitors by using various techniques, most importantly the Virtual Product Demo with 3D objects that the students can explore, disassemble and then re-assemble in a matter of seconds, 3DVR interactive objects and 360 degree panoramic virtual tours, and high quality accurate videos containing interviews with product/process experts and time and motion accurate machine / process / system demonstrations.

The developed and validated cases besides traditional teaching and learning methods, and laboratory activities, use browser-readable interactive 2D and 3D objects, animation, videos, 3D objects of real components, virtual 3D disassembly methods of objects, and simulated (virtual) factory tours that the students can create, explore and study. Our educational and computational methods introduce a novel approach to developing and running undergraduate and graduate courses in this subject area for face-to-face, honors and distance learning modes ([4], [5], and [6] to [9]).

\section{Manufacturing Cases in our Problem-based Learning Library}

In our PBL library we follow an object-oriented design, therefore our architecture includes case-based library programs that are self-contained, reusable objects built of components. Often these objects and components are text, high quality digital video, animation, 3DVR and animated 360 degree panoramas. They are open source, webenabled, delivered on the web, or in some cases in CD-ROM or DVD (to overcome transfer rate and in some countries expensive web-access bottlenecks) or fast company intranets for continuous professional development purposes.

The ways we present challenges are very similar to the way professional manufacturing engineers solve problems. This is because we first look at the real-world customer requirement, then we offer one or more solutions by explaining real-world machines, or processes, or systems, or management tasks and then we discuss further development, service, maintenance, integration, connectivity and many other issues.

In terms of delivering our cases we follow the Virtual Product Demo concept, in that we virtually take the learner with us to factories, R\&D studios, exhibitions and laboratories and give them interesting demos explained by real-world experts with challenging problems to solve. In all cases we show them high quality, interactive videos and often $3 \mathrm{D}$ objects and panoramas so that they can interrogate them and even participate in digital, virtual factory tours ([1], [10], [11] and [12]).

In terms of challenging to learn and investigate the illustrated case further we give several direct URL (web) contacts, e-mail addresses so that the learner can get in touch with key contacts and start to collaborate. We focus our questions and address exciting manufacturing engineering, product and process design, management, and computing science/ IT (Information Technology) issues. This approach helps distance learners as well as educators to work with the material in real-world classroom and/or virtually webnetworked teams ([13] to [15]). 
Specifically, our methodology suggests the following activities, or processes with continuous quality and requirement feedback-loops:

- Research and analyze the manufacturing needs, for all key processes, and then

- Develop a comprehensive system model.

- Create a pilot system, a prototype that you can realistically implement, validate, refine, then

- Create the full system as specified by your customer(s)/ sponsor(s) and then

- Validate/ test, support, maintain and educate all parties involved.

In more detail, the process by which you can achieve the above outlined and expected results can be as follows:

- Requirements analysis: What does the customer want? How can we satisfy this need at the highest quality and minimum cost? What are the manufacturing engineering solutions for satisfying customer needs? How does our competition do?

- Object oriented system analysis. (This is the 'as is' system scenario.)

- Object oriented system design. (This is the 'to be' system scenario.)

- Optional small scale test phase implementation feedback loop of the most important aspects and processes. (This is basically a prototype to be demonstrated to selected customers.)

- System design refinement feedback loop. (Based on feedback you should refine and improve your design/ system).

- Full test phase implementation feedback loop to all key aspects and processes.

- System design completion.

- Implementation and system integration.

- Final documentation (Prepare your documentation on the way preferably using interactive multimedia and on-line Internet technology. This will help you to satisfy customers as well as to save if you need to update your documentation.)

- Subject to contract, continuous system maintenance and support.

- System administration support and optional formal education at all levels to all involved. (Again, your interactive multimedia Internet based documentation could be the same as your distance learning resource material. You will save a lot! The architecture of this open source program you are viewing now is a good example for that... )

- The identification of future R\&D and other collaborative/ sales opportunities.

Our cases are object-oriented and self-contained; nevertheless, they can be integrated or grouped into different classes of objects in a lean and flexible way, just as a modern software program, or a modern manufacturing/assembly system can be integrated into different environments. This enables learners as well as instructors and managers to 'plugand-play' our cases in ways they choose rather than the way the author meant it. The methodology we follow enables basic knowledge transfer enabled with 3DVR interactive multimedia. It is highly interactive, collaborative and enables large groups as well as 
individuals to gain the same knowledge effectively.

Although this method is not for everybody because the problems as well as the solutions are interdisciplinary, often open-ended and can get complex, in all cases our solution will enhance, support and enable a wide range of interactions with real-world challenges ([16]).

The benefits of introducing manufacturing problems for students to solve using cases in a browser-readable 3DVR interactive multimedia format are manifold. The entire learning process becomes more student- versus lecture- or tutor-centered.

Students can learn by exploring versus being told, and can have as many goes at solving a problem, or exploring an idea, taking as much time as desired or is available. Mistakes made can be corrected without penalties. Multimedia tools, or a subset of such technology and a variety of media, are available during the learning process.

Self-assessment is possible. This means that students become more self-critical as they participate directly in their own learning process. The format eliminates "hidden curriculum" and self-assessment questions.

Team, group and class assessment is integrated into every module of our programs (supported by active code spreadsheets, often with embedded 3D objects, video-clips and animations) that the students can interrogate to understand either the question(s) or the answers better.

Furthermore, in our assessment programs graphs are shown illustrating individual vs. group/class benchmark assessment results. This is very useful, in particular for distance learning students, because they feel that they are equal members of the class. (Traditional, as well as e-mail, web-collaborative, telephone and personal-appointmentbased tutorial support is available if required.

The entire education process is more suited to satisfy individual needs. Since failure is not exposed in Open Learning situations, fear is not part of the learning and testing process. Students teach themselves, work on their own and the educator's role changes towards a facilitator, consultant and guide, rather than the sole information provider as in the past.

Education does not become boring, because the routine part of the material is taught by the students themselves, by means of the interactive 3DVR multimedia technology, and because the exciting or difficult parts can be reinforced by the instructor. The entire education process is more suited to satisfy individual needs from 'batch size 1 to many' at the same high quality ([2], and [4] to [6]).

To illustrate some aspects of our interactive, 3D browser readable eLearning architecture, in Figure 1, we present a typical screen segment of a case, in which we 
introduce 5-axis milling, using a multi-processor controlled CNC lathe. The challenge here, was to reach out to the manufacturing, as well as the design community, and to illustrate what advanced manufacturing processes can perform, and then feed this experience back to design. (Our partners in the case were Hardinge Inc., USA experts).

As it can be seen, the left hand side of the screen is usually hyper-linked text and small icons prompting student actions, with the fundamental text content.

In the right hand side of the screen, we offer active code, animation clips, interactive videos in 2D and 3D, 3D objects, 360 degree panoramas and virtual facility tours, and others, that enhance the learning process, and together with the text, images and other media re-enforce the subject area.

According to our experiences, such multi-facetted computing support in education offers a well-rounded experience, that is significantly more enjoyable to learn, than using traditional methods. (Please note, that our original screens are in high quality, full screen and full color graphics, that we had to reduce in size and quality to fit the format requirements of this paper. If interested, please look up http://www.cimwareukandusa.com, and then click on the Case Library icon to see these and other screens in high quality.) 


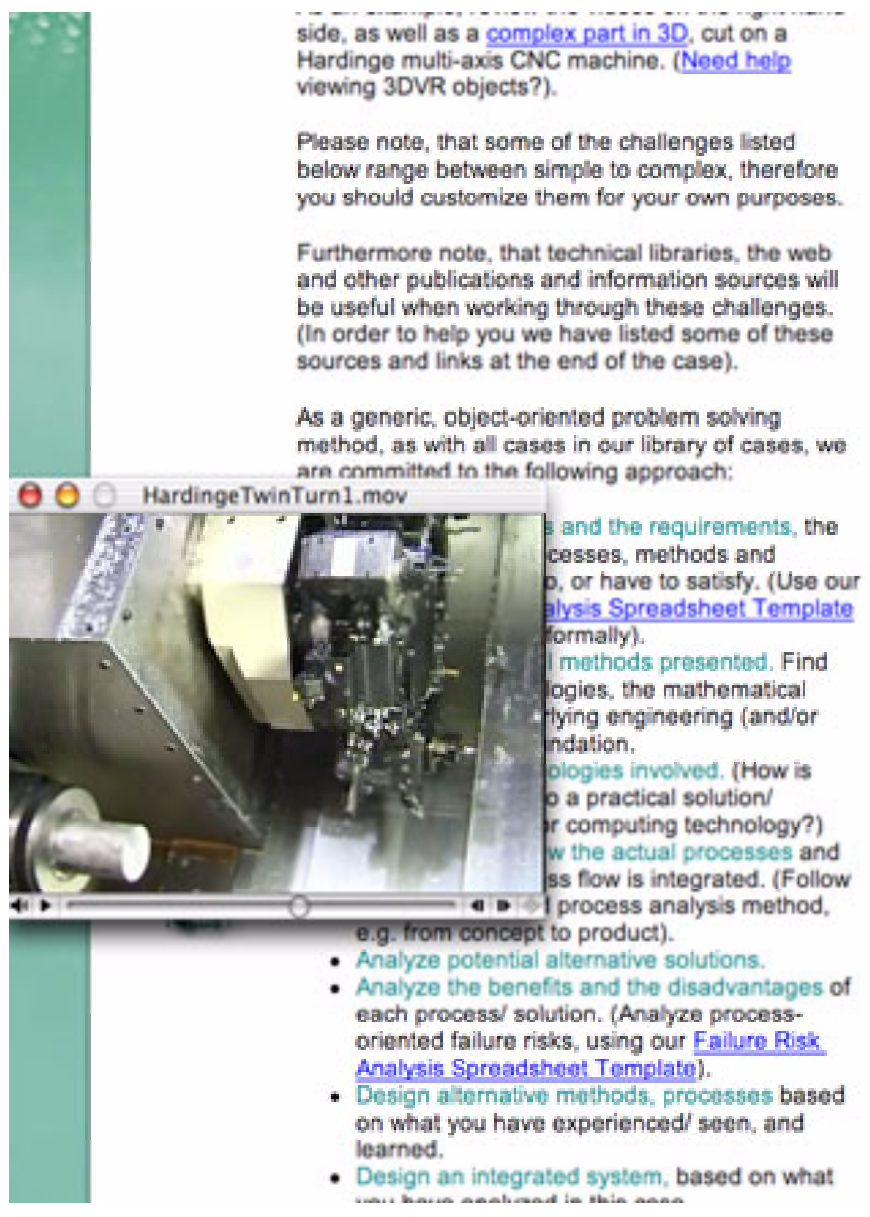

separate wndow, so that you can see the text on the left hand side of this screen together with the video clip playing.
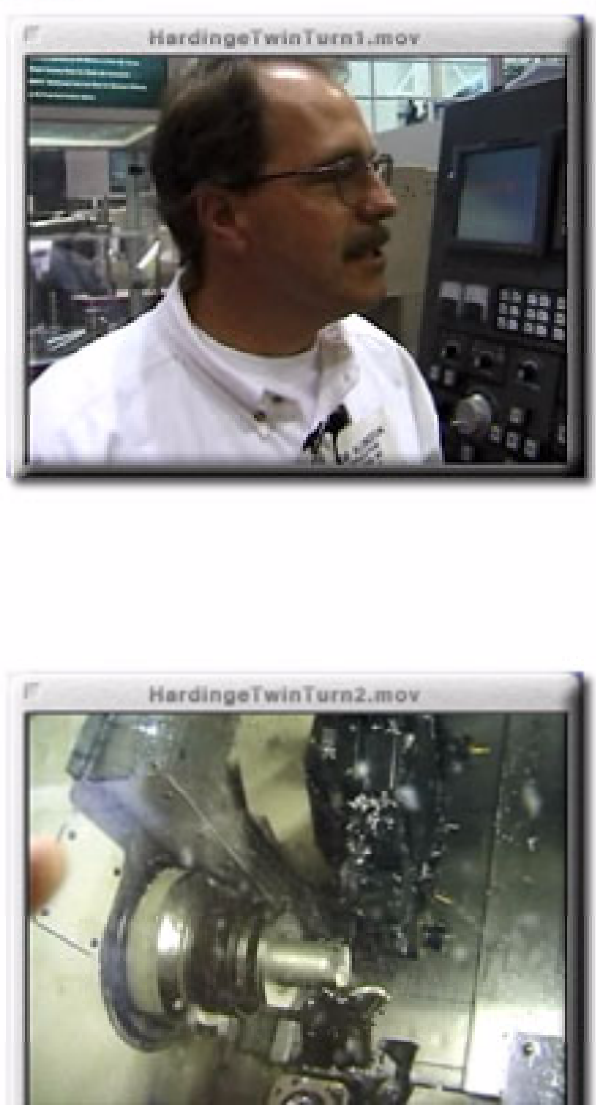

Figure 1. A typical screen segment of our interactive 3D multimedia screens in the Case Based Learning Library.

Figure 2 (below) illustrates further screen segments, that enable students to actively manipulate real-world virtual 3D objects, and explore them according to their own interest. (Note, that according to our experience, this approach keeps the students interested in the subject they learn, because they can actively interact with the computer, showing them exciting 3D interactive animations, and active code they can run with their own data, all under their control).

Proceedings of the 2003 American Society for Engineering Education Annual Conference \& Exposition. Copyright (C) 2003, American Society for Engineering Education. 


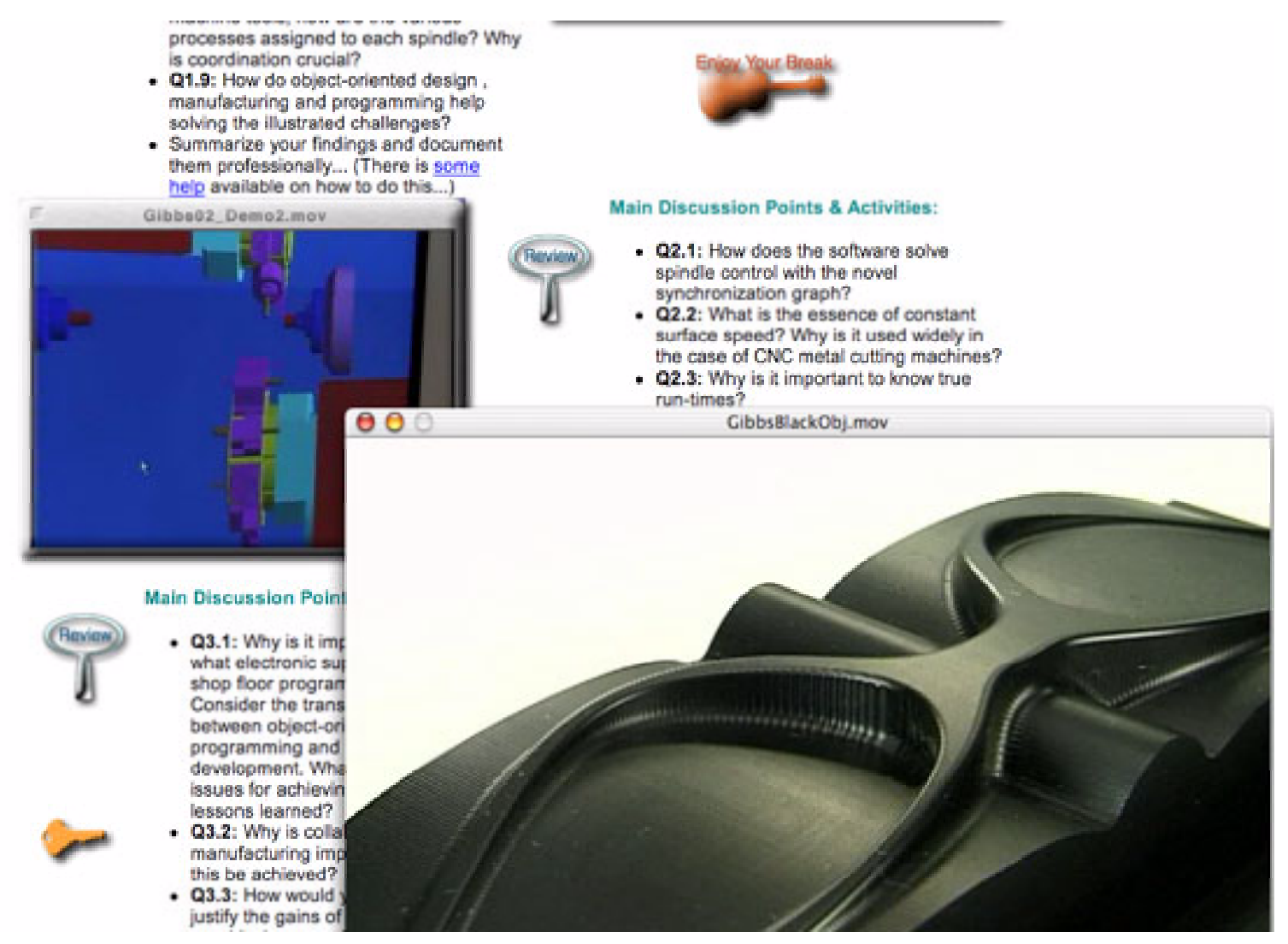

Figure 2 illustrates an interactive 3D virtual reality object, that enables students to explore an-in-depth view of the discussed manufacturing subject area. (Please note, that our original screens are in high quality, full screen and full color graphics, that we had to reduce in size and quality to fit the format requirements of this paper. If interested, please look up http://www.cimwareukandusa.com, and then click on the Case Library icon to see these and other screens in high quality.)

\section{Summary and Conclusions}

Our 3D multimedia learning material have been validated and tested in several industry and university (live and virtual) classes, involving hundreds of undergraduate and graduate students at NJIT in Industrial Engineering, Mechanical Engineering, Computing Science and Information Technology, as well as on a wider US and international basis, at Dundee University in Scotland, at Nottingham in the UK, at Imperial College in London, at Old Dominion in the USA, at the University of Michigan, in Ann Arbor, in Sweden, in Hungary, in Mexico, in Hong Kong, in Singapore, in Switzerland, at Kyoto and Kobe Universities in Japan, and at many other institutions and companies world-wide. We are pleased to report that our methods, and several 3D multimedia resources have been adopted for university and company intranets for eLearning.

Due to the open, web-browser readable nature of our approach, each object/module is customizable, extendible and editable. This popular feature allows students and faculty to

Proceedings of the 2003 American Society for Engineering Education Annual Conference \& Exposition. Copyright (C) 2003, American Society for Engineering Education. 
become simultaneously authors as well as readers. (In order to maintain integrity and quality, obviously, the core documents are maintained permanently only by the document owners).

The most important design feature of our object oriented system architecture is that there is only one core, reusable electronic document, built of 3D web-objects, and active code, that has to be authored and maintained. This enables a wide variety of users/viewers to occasionally become authors (via the appropriate security gates and web-technology) feeding useful knowledge into the content of the object and component oriented architecture.

This work is the result of several years of on-going research. It started in 1977-78 when Paul G Ranky has developed an FMS (Flexible Manufacturing System) object-oriented database and then later, in 1984 by Ranky at Nottingham and Siemens-Plessey in the UK, and then in 1992 when together with Mick F. Ranky, supported by CIMware Ltd., http://www.cimwareukandusa.com and FESTO Ltd. an interactive multimedia CD-ROM was developed as an electronic support system for servo-pneumatic positioning, as well as part of another project for bio-medical engineering with Prof. T. Pato in Berne, Switzerland. In 1997 Paul G. Ranky and Mick F. Ranky developed a 3D browser readable, virtual computer disassembly method, supported by industry, that has led to several other R\&D grants (including major DOD grants for NJIT) and publications, including the 3D Multimedia Case Based Library (1995 to date).

Since then the topic as well as the architecture has evolved into a robust, object-oriented knowledge management architecture with 3D web-objects, supported by several companies and institutions, including FESTO Inc. USA, GenRad, Inc., The Nottingham Innovative Manufacturing Center, IMI, Ford, Rolls Royce, Ratheon, PSE\&G, GibbsCAM, GenRad, Cincinnati Machines, Fanuc Robotics, MCI-WorldCom, IBM, Okuma, BMW, Motorola, Sony, GE Fanuc, Yamazaki Mazak, Bosch and many others. Our efforts have been validated and strongly supported most importantly by our undergraduate and graduate engineering, engineering management and computing students at NJIT, and elsewhere in the world, who have worked through different versions of our objects and helped us shaping it to its current, still evolving, nevertheless already mature and very robust truly multi-platform (meaning Apple Mac, OS 9 and OS X, PC Win 98, 2000, NT, XP, Linux and Unix compatible) format.

We would like to thank for the continuous support of our students, the companies and organizations, and pleased to report that our efforts are moving on with an increasingly positive energy flow in all of us involved.

\section{Live Software Demonstration}

During the presentation of this paper at the conference there will be several live software demonstrations, illustrating the novel interactive 3D multimedia, as well as the active code and video-clips, that a printed paper can never truly illustrate. 
Furthermore during discussions further, in-depth software demonstrations will be given, and questions will be answered during the conference using off-line, and optionally wireless Internet access (based on availability).

\section{Bibliographic Information}

[1] Frazer, A. and Ranky, P.G.: A Case-based Introduction to the National Electronics Manufacturing Initiative (NEMI) Plug and Play Factory Project; An interactive multimedia publication with 3D objects, text and videos in a browser readable format on CD-ROM/ intranet by

http://www.cimwareukandusa.com, CIMware USA, Inc. and CIMware Ltd., UK, ISBN 1-872631-41-x, 2000, 2001. Multimedia design \& programming by P G Ranky and M F Ranky.

[2] Ranky P G: Interactive Multimedia for Engineering Education, European Journal of Engineering Education, Vol. 21, No. 3, 1996, p. 273-293.

[3] Ranky, P. G.: Some Analytical Considerations of Engineering Multimedia System Design within an Object Oriented Architecture, IJCIM (International Journal of CIM, Taylor \& Francis, London, New York) ), Vol. 13, No. 2, May 2000, p. 204-214

[4] Ranky, P G, Caudill, R. J., Limaye K., Alli, N., Satishkumar ChamyVelumani, Apoorva Bhatia and Manasi Lonkar A Web-enabled Virtual Disassembly Manager (web-VDM) for Electronic Product / Process Designers, Disassembly Line Managers and Operators, a UML (Unified Modeling Language) Model of our Generic Digital Factory, and Some of Our Electronic Support System Analysis Tools, ADAM with IT (Advanced Design And Manufacturing), An international intern et registered R\&D journal hosted by: http://www.cimwareukandusa.com listed and indexed by the Association of Research Libraries, Washington DC, USA, and the Edinburgh Engineering Virtual Library, UK. USA, 5 p., Vol. 3., May 2002

[5] Ranky, P G: Automotive Welding and Assembly Line Network Simulation Case Studies and Results, Industrial Robot: An International Journal, Vol. 30, No. 2, Emerald Publishing Ltd., England (Accepted Draft Research Paper in preparation)

[6] Ranky, P G and Ranky, M F: Engineering Multimedia CD-ROMs with Internet Support for Educating the Next Generation of Engineers for Emerging Technologies (A Presentation with an Interactive Multimedia CD-ROM Demonstration) ETFA '97, The 6th International IEEE Conference on Emerging Technologies and Factory Automation, Los Angeles, USA, September 9-12, 1997. Proceedings p.76-81.

[7] Ranky, P G.: An Object Oriented Virtual Concurrent Engineering Model and Product Demonstrator Case Study, Japan-USA International Symposium on Flexible Automation, ASME (American Society of Mechanical Engineers), July, 2000, Ann Arbor, MI, Conference Proceedings.

[8] Ranky, P.G, One-Jeng and Surjanhata, H: Digital Educational Knowledge Assets, International Engineering Education Conference, August 2000, Taipei, Taiwan, Conference Proceedings

[9] Ranky, P G, Herli Surjanhata, One-Jang Jeng, Geraldine Milano: The Design and Implementation of Digital Educational Knowledge Assets (DEKA) with Software Demonstration (An NJIT and Industry Sponsored R\&D Project. ASEE (American Society of Engineering Education) NJ Spring Conference, April, 2001 (eProceedings)

Proceedings of the 2003 American Society for Engineering Education Annual Conference \& Exposition. Copyright (C) 2003, American Society for Engineering Education. 
[10] Ranky, P G: An Object Oriented Model and Cases of Design, Manufacturing, and IT Knowledge Management Over the 3D- enabled Web and Intran ets, INFORMS International Conference, USA, July, 2001, (in the Proceedings).

[11] Ranky, P G: The Design and Implementation of a Case-based Learning Library for Engineering, Management and IT with 3D web-objects, Third Annual Faculty Best Practices Showcase, Invited Paper, NJ Higher Education Network, Proceedings, NJIT, Newark, NJ, Nov 9, 2001

[12] Ranky, P G, Ranky M F, Flaherty, M, Sands, S and Stratful, S: Servo Pneumatic Positioning, An Interactive Multimedia Presentation on CD-ROM (650 Mbytes, 330 interactive screens, 70 minutes of digital videos, animation and over 300 photos), published by CIMware (IEE and IMechE Approved Professional Developer), March 1996. Multimedia design \& programming by P G Ranky and M F Ranky.

[13] Ranky, P G: An Introduction to Advanced Manufacturing Processes Using 3D Virtual Reality Objects (DEKA, Digital Educational Knowledge Assets). An Interactive Multimedia Presentation on CDROM with off-line Internet support by CIMware (IEE and IMechE Approved Professional Developer), 2000. ISBN 1-872631 08 8. Multimedia design \& Programming by P G Ranky and M F Ranky.

[14] Upcraft, S and Ranky, P G: A Case Based Introduction to Rapid Prototyping Solutions, An Interactive Multimedia Presentation on CD-ROM with off-line Internet support (650 Mbytes, approx. 150 interactive screens, 50 minutes of digital videos, animation and 3DVR objects), by CIMware (IEE and IMechE Approved Professional Developer), 2000-2002, Multimedia design \& Programming by P G Ranky and M F Ranky.

[15] Gibbs, B.. and Ranky, P.G.: A Case-based Introduction to Advanced CAM (Computer Aided Manufacturing); An interactive multimedia publication with 3D objects, text and videos in a browser readable format on CD-ROM/ intranet by http://www.cimwareukandusa.com, CIMware USA, Inc. and CIMware Ltd., UK, ISBN 1-872631-45-2, 2001-2002. Multimedia design \& programming by P G Ranky and M F Ranky.

[16] Dunkerley, G., Norton, N. and Ranky, P.G.: A Case-based Introduction to IMI Norgren's Reengineering Project at Kenilworth, UK; An interactive multimedia publication with 3D objects, text and videos in a browser readable format on CD-ROM/ intranet by http://www.cimwareukandusa.com, CIMware USA, Inc. and CIMware Ltd., UK, ISBN 1-872631-40-1, 2001-2002. Multimedia design \& programming by P G Ranky and M F Ranky.

\section{Biographical Information}

Paul G. Ranky, PhD Full Tenured Professor, The Department of Industrial and Manufacturing Systems Engineering, New Jersey Institute of Technology, NJ, USA. For a biographical sketch, including current projects and recent publications, many on-line, please visit:

http://www.cimwareukandusa.com/aboutpgr.htm and then hyper-link as appropriate.

Proceedings of the 2003 American Society for Engineering Education Annual Conference \& Exposition. Copyright (C) 2003, American Society for Engineering Education. 